Tạp chí Khoa học và Công nghệ biển T11 (2011). Số 3. Tr 1 - 13

\title{
ỨNG DUNG VIỄN THÁM VÀ GIS TRONG THEO DÕI VÀ TÍNH TOÁN BIẾN ĐộNG ĐƯờNG BỜ KHU VỰC PHAN THIẾT
}

\author{
PHẠM THỊ PHƯƠNG THẢO
}

Viện Hải dương học

HỒ ĐìnH DUẨN

Viện Tài nguyên, Môi trường và Phát triển bền vững tại TP. Huế

\author{
ĐẶNG VĂN TỎ
}

Trường Đại học Khoa học Tự nhiên Tp. HCM

\begin{abstract}
Tóm tắt: Bằng các kỹ thuật hiện đại tì̀ công nghệ viễn thám và GIS, việc theo dõi và tính toán tốc độ thay đổi đường bờ được thực hiện một cách nhanh chóng và hiệu quả. Với nguồn ảnh Landsat đa thời gian, bức tranh so bộ về sư biến động đuờng bờ khu vưc Phan Thiết trong giai đoạn 1973 - 2004 đuợc vẽ lại. Bên cạnh đó, vói sụ hỗ trợ đắc lục tù phần mỏ rộng DSAS (Digital Shoreline Analysis System) của công cu GIS, tốc độ thay đổi đường bò khu vưc Hàm Tiến đã được tính toán trong các giai đoạn truớc và sau khi có các công trình ven bò:
\end{abstract}

\section{GIỚI THIỆ}

Ngày nay, với sự tích hợp khéo léo của công nghệ viễn thám và GIS, việc theo dõi và tính toán các biến động đường bờ được thực hiện khá nhanh chóng và hiệu quả. Ngoài những chuyến thực địa bằng các dụng cụ và thiết bị truyền thống, hiện nay, chúng ta có thể thực hiện đo vẽ đường bờ bằng các thiết bị GPS, bằng các ảnh kỹ thuật số, hoặc bằng hệ thống máy camera video $[4,5,6,12]$. Bên cạnh đó, đường bờ còn có thể thu được trên một phạm vi rộng lớn từ các ảnh máy bay và ảnh vệ tinh. Từ các dữ liệu đó, việc đánh giá và phân tích diễn biến đường bờ được thực hiện trực tiếp hoặc có thể đưa vào công cụ GIS để tính toán tốc độ thay đổi đường bờ.

Tuy công nghệ viễn thám và GIS ở Việt Nam phát triển muộn hơn rất nhiều so với thế giới nhưng nước ta cũng đã đạt được một số kết quả nghiên cứu nhất định. Về ứng dụng viễn thám trong phân tích và đánh giá biến động đường bờ, một số nghiên cứu đã 
được thực hiện ở một số khu vực, tập trung chủ yếu là vùng đồng bằng sông Hồng và sông Cửu Long, và một số khu vực cửa sông như Lộc An, Cửa Đại, Thuận An... Cụ thể như, với dữ liệu ảnh Landsat, SPOT và ảnh máy bay, nhóm tác giả Phạm Viết Cường cùng cộng sự đã nghiên cứu sự thay đổi vùng ven bờ và cửa sông Hải Phòng từ năm 1975 đến năm 1988 [15]. Biến động đường bờ các cửa sông chính: cửa Trà Lý, cửa Ba Lạt, cửa Văn Úc và cửa Đáy thuộc dải ven biển đồng bằng sông Hồng từ năm 1926 đến 1995 được nhóm tác giả Nguyễn Tứ Dần và Nguyễn Thế Tiệp thực hiện bằng dữ liệu ảnh SPOT, Landsat, bản đồ địa hình, ảnh máy bay [8]. Các biến đổi lịch sử khu vực cửa sông Lộc An từ ảnh viễn thám đa thời gian từ năm 1953 đến năm 2002 cũng được thực hiện bởi nhóm tác giả Phạm Bách Việt từ ảnh Landsat và ảnh máy bay [9]. Với mục đích quản lý vùng ven bờ, tác giả Nguyễn Hạnh Quyên sử dụng kỹ thuật viễn thám khoanh vùng đất ngập nước tại khu vực vịnh Hạ Long, đồng thời cho kết quả sự thay đổi rừng ngập mặn cũng như sự thay đổi bờ biển trong những khoảng thời gian khác nhau từ 1988 đến 2002 bằng ảnh Landsat TM và ETM+ [7]. Việc phát hiện sự thay đổi bờ biển tại vùng ven bờ cửa sông Cửu Long trong thời gian 1989 đến 2004 được thực hiện bởi nhóm tác giả Trần Thị Vân và Trịnh Thị Bình [14].

Về ứng dụng GIS trong tính toán định lượng tốc độ thay đổi đường bờ, một số kết quả cũng đã thu thập được. Với dữ liệu đường bờ được số hóa từ các dữ liệu khảo sát đo đạc từ năm 1905 đến 1992 ở khu vực Hải Hậu, Nam Định, các tác giả Đặng Văn Tỏ và Phạm Thị Phương Thảo đã trình bày một số kết quả tính toán tốc độ thay đổi đường bờ từ các phương pháp thống kê có sẵn trong phần mở rộng DSAS của công cụ GIS [3]. Tương tự, đường bờ lịch sử khu vực Phan Thiết, Bình Thuận từ năm 1973 đến 2002 được rút trích từ ảnh Landsat và tốc độ thay đổi đường bờ khu vực này được tính toán nhanh chóng bằng phần mở rộng DSAS cũng được nhóm tác giả Phạm Thị Phương Thảo, Hồ Đinh Duẩn và Đặng Văn Tỏ thực hiện [10].

Với sự phát triển cực nhanh về dịch vụ du lịch từ năm 1995, Phan Thiết đang phải đối mặt với hiện tượng xói lở nghiêm trọng do tác động của các công trình ven bờ [2]. Do đó, Phan Thiết được chọn làm khu vực nghiên cứu (hình 1 ). Bài báo này trình bày hai vấn đề: các phân tích diễn biến đường bờ theo thời gian giai đoạn 1973 - 2004 và kết quả tính toán tốc độ thay đổi đường bờ hàng năm bằng DSAS tại khu vực Phan Thiết trước và sau khi có công trình ven bờ. 


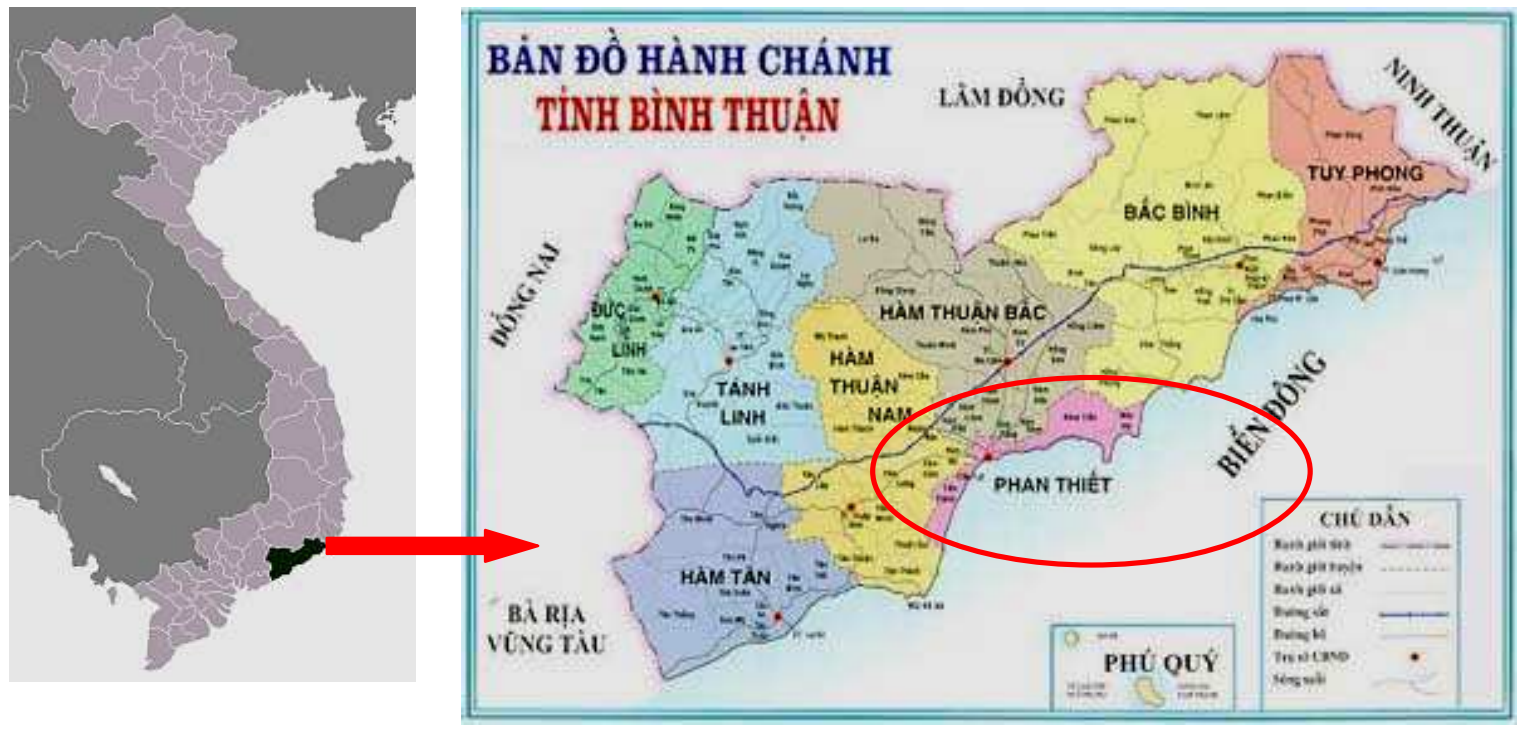

Hình 1: Khu vực nghiên cứu

\section{II. ĐIỀU KIỆN TỰ NHIÊN KHU VỤ̉C NGHIÊN CÚ̉}

\section{1. Đặc điểm khí tượng}

Phan Thiết chịu ảnh hưởng của hai chế độ gió mùa: gió mùa Đông Bắc vào mùa đông và gió mùa Tây Nam vào mùa hè. Gió mùa Đông Bắc bắt đầu thổi từ tháng 11 và kéo dài tới tháng 3 năm sau. Vận tốc gió trung bình trong mùa này vào khoảng $8-10 \mathrm{~m} / \mathrm{s}$. Gió mùa Tây Nam bắt đầu từ tháng 6 đến tháng 9 . Vận tốc gió trung bình khoảng $6-8$ $\mathrm{m} / \mathrm{s}$. Tháng $4-5$ là giai đoạn chuyển tiếp từ gió mùa mùa đông sang gió mùa mùa hè và tháng 9 - 10 là giai đoạn chuyển tiếp ngược lại [1].

\section{2. Đặc điểm thủy văn}

Do chịu tác động của hệ thống gió mùa Đông Bắc và Tây Nam, Phan Thiết có hai chế độ sóng gió chủ yếu. Về mùa đông, sóng có hướng chiếm ưu thế là hướng Đông Bắc, có khi chuyển về Đông, độ cao sóng trung bình dao động từ $1,2-2,0 \mathrm{~m}$. Trong trường hợp gió có hướng Tây Bắc chiếm ưu thế thì sóng có hướng chính là Nam và Tây Nam, sóng với hướng này có độ cao trung bình $0,7-1,5 \mathrm{~m}$. Tuy nhiên, chế độ sóng vào thời kỳ này thường không ổn định vì thỉnh thoảng bị ảnh hưởng của bão và áp thấp nhiệt đới, khi đó sóng ngoài khơi và ven bờ thường quan sát thấy không đồng nhất $[1,11]$.

Thủy triều vùng ven biển Bình Thuận khá phức tạp vì nằm trong khu vực chuyển tiếp giữa chế độ nhật triều không đều ở phía Bắc (tiêu biểu là Qui Nhơn) và bán nhật triều 
không đều ở phía Nam (Vũng Tàu) [1]. Dao động triều khoảng $2 \mathrm{~m}$. Chế độ thủy triều cũng gây ra dòng chảy mạnh ven bờ có thể lên đến $50-70 \mathrm{~cm} / \mathrm{s}$ [1].

\section{PHƯƠNG PHÁP NGHIÊN CÚU}

\section{Viễn thám}

Để đạt hiệu quả hơn trong việc rút trích đường mực nước cho khu vực bờ biển vịnh Phan Thiết, phương pháp kết hợp phân tích giữa giá trị ngưỡng và ảnh tỷ số được áp dụng cho ảnh Landsat. Ưu điểm của phương pháp kết hợp này là loại bỏ nhiễu do vùng nghiên cứu có độ phủ thực vật cao và nhiễu do vùng sóng vỡ. Công thức cụ thể như sau:

- Đối với Landsat MSS:

$(\mathrm{B} 3+\mathrm{B} 4) / \mathrm{B} 1$

- Đối với Landsat TM, ETM+: (B5+B7)/B2 có kết hợp B7

Do không có số liệu đo đạc thực tế cũng như bản đồ địa hình đáy tỷ lệ cao của khu vực vịnh Phan Thiết để phục vụ cho việc hiệu chỉnh triều, cũng như do độ phân giải không gian không cao $(30 \mathrm{~m})$ của ảnh Landsat nên việc hiệu chỉnh triều được bỏ qua. Vì thế, kết quả đường mực nước rút trích được xem như đường bờ.

\section{GIS}

Sau khi hoàn thành tập dữ liệu đường bờ, việc tính toán tốc độ thay đổi đường bờ được thực hiện bằng DSAS, phần mở rộng của ArcView do Thieler và cộng sự viết bằng ngôn ngữ Avenue trên phần mềm ArcView [13]. Công việc tính toán và phân tích đường bờ được tiến hành như sau:

1. Xác định đường chuẩn (baseline) và các đường bờ tính toán (shoreline)

2. Tạo các tuyến cắt ngang vuông góc bờ (transect)

3. Tính toán tốc độ thay đổi đường bờ

Trong DSAS có nhiều phương pháp tính toán thống kê khác nhau, như phương pháp tính tốc độ thông qua điểm đầu - điểm cuối (End-Point Rate), phương pháp tính tốc độ trung bình AOR (Average Of Rate), phương pháp hồi quy tuyến tính (Linear Regression), phương pháp gập gãy (Jack-Knife Rate)... Tùy theo chất lượng và số lượng đường bờ ta sẽ chọn phương pháp thống kê phù hợp nhất. Dựa trên dữ liệu thu thập được, phương pháp hồi quy tuyến tính được chọn để phân tích kết quả. 


\section{DŨ LIỆU SỬ DỤNG}

Nguồn dữ liệu ảnh Landsat thu thập từ trang web của Cơ quan Địa chất Hoa Kỳ (USGS) (http://edcsns17.cr.usgs.gov/EarthExplorer/). Các ảnh đã được nắn chỉnh và theo hệ qui chiếu WGS-84 UTM, áp dụng cho vùng 49. Danh sách các ảnh tại khu vực vịnh Phan Thiết được thu thập và được ghi trong bảng 1 .

Bảng 1: Các ảnh Landsat tại khu vực vịnh Phan Thiết

\begin{tabular}{|c|c|c|c|c|}
\hline STT & Loại ảnh & Độ phân giải (m) & Ngày chụp & Năm qui ước \\
\hline 1 & Landsat 1 MSS & 57 & $01 / 01 / 1973$ & 1973 \\
\hline 2 & Landsat 2 MSS & 57 & $31 / 01 / 1976$ & 1976 \\
\hline 3 & Landsat 5 TM & 28.5 & $30 / 12 / 1990$ & 1991 \\
\hline 4 & Landsat 7 ETM+ & 30 & $13 / 11 / 1999$ & 2000 \\
\hline 5 & Landsat 7 ETM+ & 30 & $01 / 12 / 2000$ & 2001 \\
\hline 6 & Landsat 7 ETM+ & 30 & $05 / 01 / 2002$ & 2002 \\
\hline 7 & Landsat 7 ETM+ & 30 & $24 / 01 / 2003$ & 2003 \\
\hline 8 & Landsat 5 TM & 30 & $20 / 12 / 2004$ & 2005 \\
\hline
\end{tabular}

Các ảnh Landsat trên được chụp trong khoảng thời gian từ giữa tháng 11 đến cuối tháng 1 năm sau, trùng với thời kỳ gió mùa Đông Bắc. Do đó, việc tính toán và phân tích sự thay đổi đường bờ chỉ được trong thời kỳ gió mùa Đông Bắc và sự biến đổi nó qua các năm.

\section{KẾT QUẢ VÀ THẢO LUẬN}

Nhằm tiện việc phân tích, khu vực nghiên cứu được chia thành 5 khu vực nhỏ từ trái sang phải và được đánh dấu từ 1 đến 5 như trên hình 2 . Các khu vực 1,3 và 5 là các khu vực tập trung dân cư, một số nơi có bờ là các vách đá. Khu vực 2 là đoạn bờ Đồi Dương, nằm giữa hai cửa sông: Cái và Cà Ty. Đây là đoạn bờ có dịch vụ du lịch phát triển. Khu vực 4 là đoạn bờ Hàm Tiến, Mũi Né nơi tập trung hầu hết các khách sạn và các khu nghỉ dưỡng cao cấp phục vụ du lịch trong và ngoài nước. 


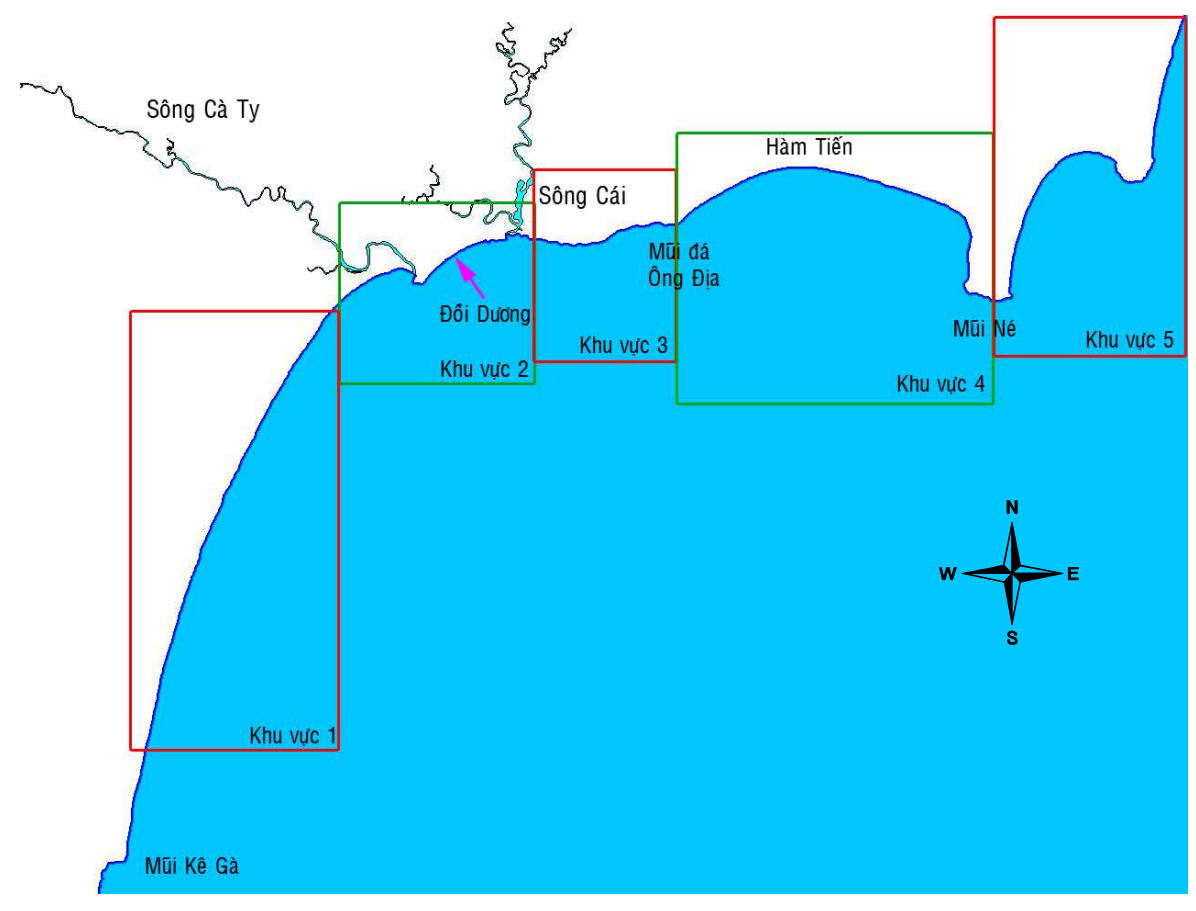

Hình 2: Khu vực nghiên cứu

Do khu vực 1,3 và 5 có đường bờ tương đối ổn định và ít xói lở như trình bày trong hình 3 , vì vậy, chỉ khu vực 2 và khu vực 4 được khảo sát và nghiên cứu chi tiết.

Khu vực 2 hay khu vực Đồi Dương ở gần cửa sông nên đường bờ có sự biến động đáng kể qua nhiều năm từ 1973 đến 2005 như hình 4. Ngoài tác động của các quá trình động lực ven bờ, đường bờ khu vực này còn chịu ảnh hưởng bởi các quá trình vận chuyển phù sa đổ ra từ sông. Sự hiện diện của các kè cảng ở cửa sông Cái và cửa sông Cà Ty cũng góp phần tác động đến quá trình vận chuyển trầm tích. Tất cả các yếu tố trên đã làm cho quá trình biến đổi đường bờ nơi đây khá phức tạp.

Ở cửa sông Cà Ty, vào năm 1973, có sự xuất hiện của doi cát ở phía bờ Nam. Trong năm 1976, vật liệu phù sa không bị đẩy qua khu vực phía Nam mà tích tụ lại bờ bắc, hình thành doi cát ngay tại phía Bắc của cửa sông. Đến năm 1991, khu vực cửa sông bắt đầu có sự biến đổi khá phức tạp với hai doi cát ở cả hai bên cửa sông, đặc biệt là sự hình thành doi cát dài trên bờ Bắc chắn ngang cửa sông. Vào những năm 90 của thế kỷ trước, kè cảng ở phía Nam cửa sông được xây dựng, góp phần ổn định đoạn bờ này. Vật liệu được tích tụ bên phía Nam của kè. Năm 2000, kè phía Bắc cửa sông Cà Ty được xây dựng, góp phần ngăn chặn quá trình hình thành doi cát tại phía Bắc của cửa sông. Hiện tượng xói lở bắt đầu xuất hiện ở phía bên trái kè phía Nam cửa sông Cà Ty trong năm 2002. Nguyên nhân là do có quá trình đổ vật liệu lấn biển của công ty tư nhân, và cũng từ đó bắt đầu xuất hiện 
công trình đê biển để bảo vệ đoạn bờ này. Vì thế, từ sau năm 2002, đường bờ khu vực cửa sông Cà Ty tương đối ổn định.

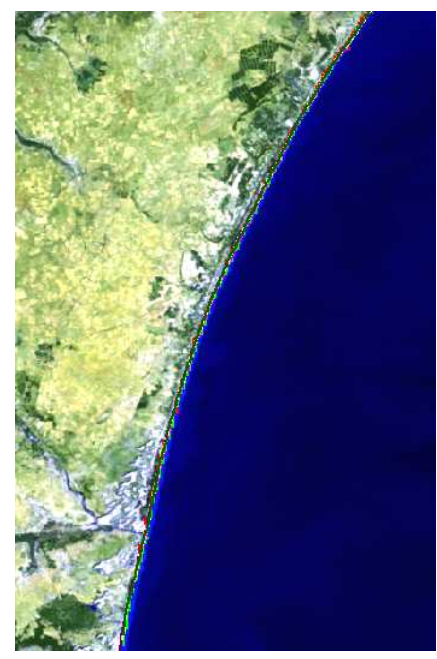

Khu vực 1

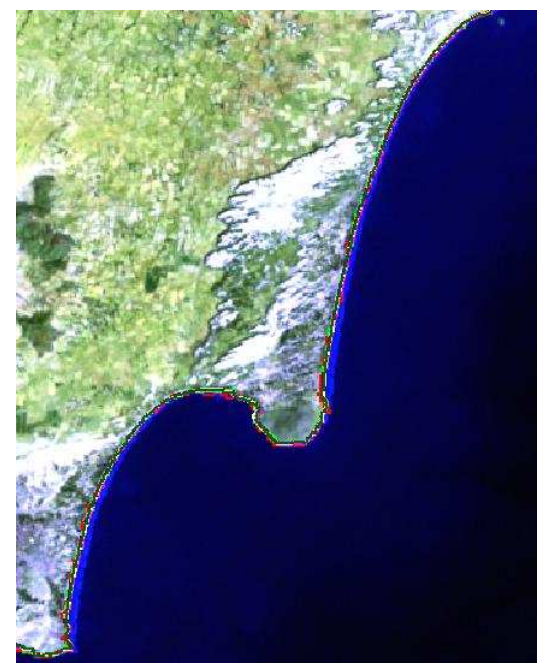

Khu vực 5

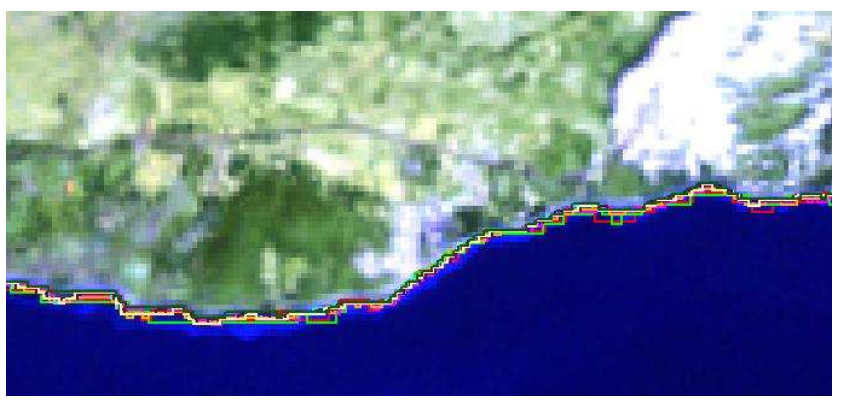

Khu vực 3

Hình 3: Kết quả đường bờ khu vực 1,3 và 5

Ở cửa sông Cái, vào năm 1976 nơi đây bắt đầu hình thành doi cát nhỏ phía Bắc cửa sông. Doi cát này tiếp tục phát triển và kéo dài về phía Nam cho đến các năm 1991, 2000, 2001. Nguyên nhân có thể là do dòng chảy từ sông đổ ra kết hợp với các quá trình ven bờ tạo nên sự lắng đọng của phù sa tại khu vực gần cửa sông. Năm 2002, khu vực cửa sông được mở lại, làm cho phía Nam của cửa sông hình thành các doi cát xoắn dọc bờ. Vào đầu năm 2003, kè cảng phía Nam của cửa sông Cái chưa được xây xong, nơi đây vẫn còn tồn tại một vài doi cát nhỏ. Năm 2005, các doi cát này mất dần sau khi có sự hiện diện của kè phía Nam. Khu vực cửa sông được cố định nhằm ổn định dần các quá trình biến đổi tại đây. 


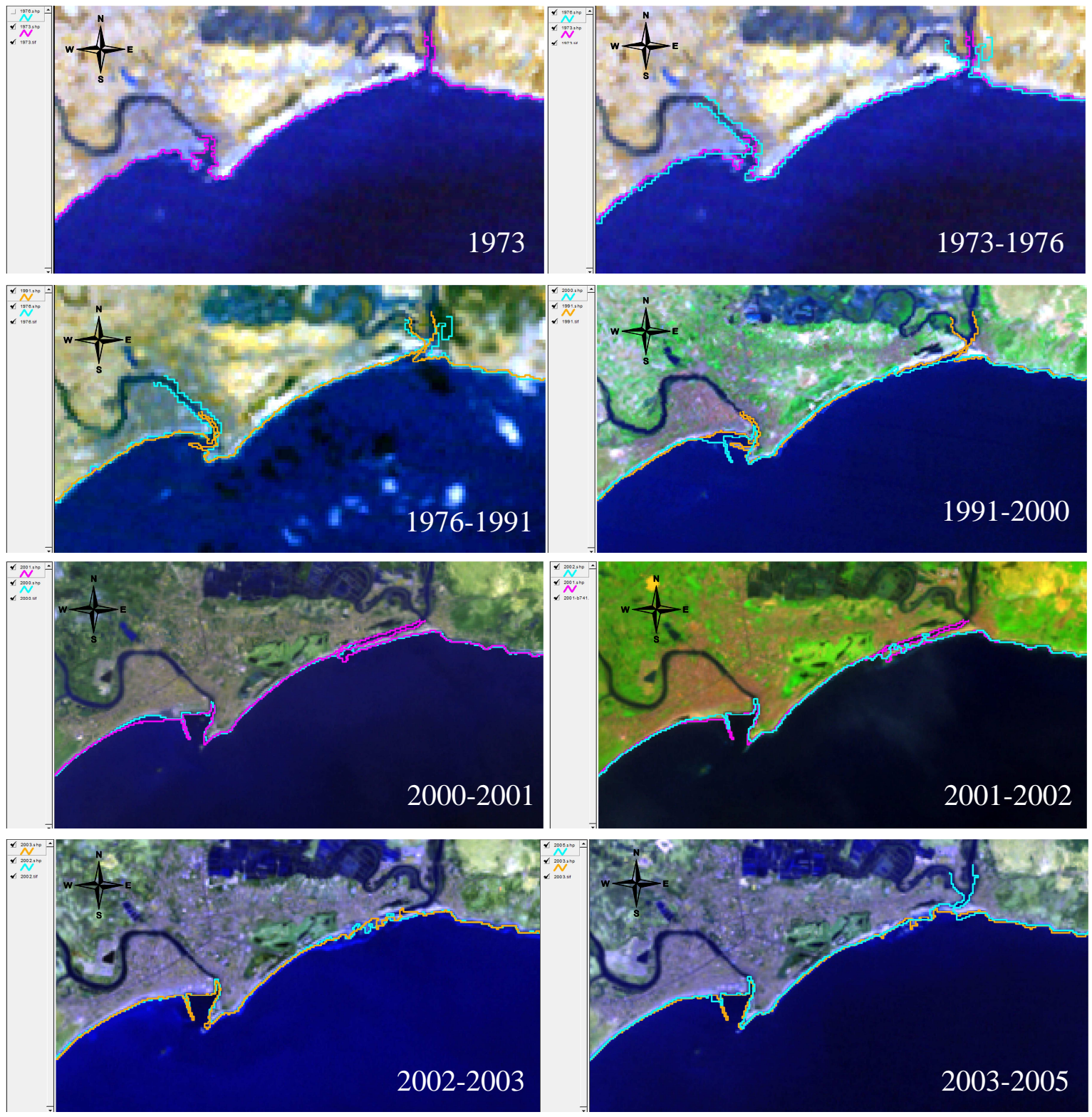

Hình 4: Sự thay đổi đường bờ khu vực 2 (Đồi Dương) từ năm 1973 đến 2005

Khu vực 4 hay khu vực Hàm Tiến có đường bờ biến động ít và tương đối ổn định hơn so với trường hợp của khu vực Đồi Dương. Do khu vực này nằm khuất sau Mũi Né nên nó không bị ảnh hưởng lớn của gió Đông Bắc vào cuối năm. Về sóng biển, khu vực 4 chủ yếu có trường sóng khúc xạ từ trường sóng Đông Bắc ngoài khơi truyền vào. Nhằm chống xói lở, khu vực này đã xây dựng các công trình bảo vệ bờ biển từ cuối thập niên 90 của thế kỷ trước. Do vậy, khi phân tích biến động đường bờ tại khu vực này, hai giai đoạn 
xác định sự có mặt của công trình sẽ được lần lượt trình bày: giai đoạn trước năm 2000 và giai đoạn sau năm 2000.

Từ giai đoạn 1973 - 2000, dòng vật chất di chuyển từ Bắc xuống Nam (từ phải qua trái trên hình 5), cho nên khu vực phía Bắc đường bờ có xu hướng lùi vào đất liền và khu vực phía Nam thì ngược lại và lấn ra biển.

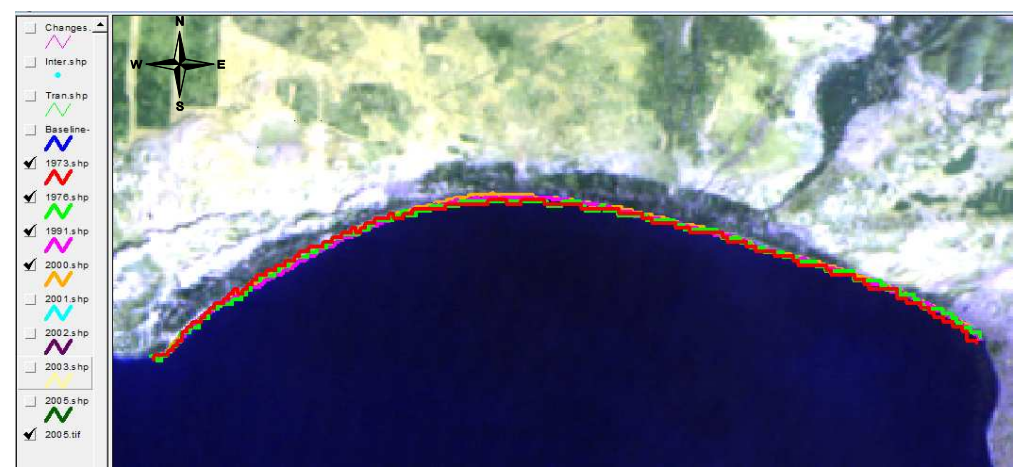

Hình 5: Sự thay đổi đường bờ khu vực 4 (Hàm Tiến) từ năm 1973 đến 2000

Từ giai đoạn 2000 - 2005, các công trình bảo vệ đường bờ ở các khu khách sạn và nghỉ dưỡng xuất hiện, quy luật biến động đường bờ nơi đây bắt đầu thay đổi (hình 6 ). Cụ thể, khu vực gần mũi đá Ông Địa bắt đầu bị xói lở nghiêm trọng trong giai đoạn 2003 2005.

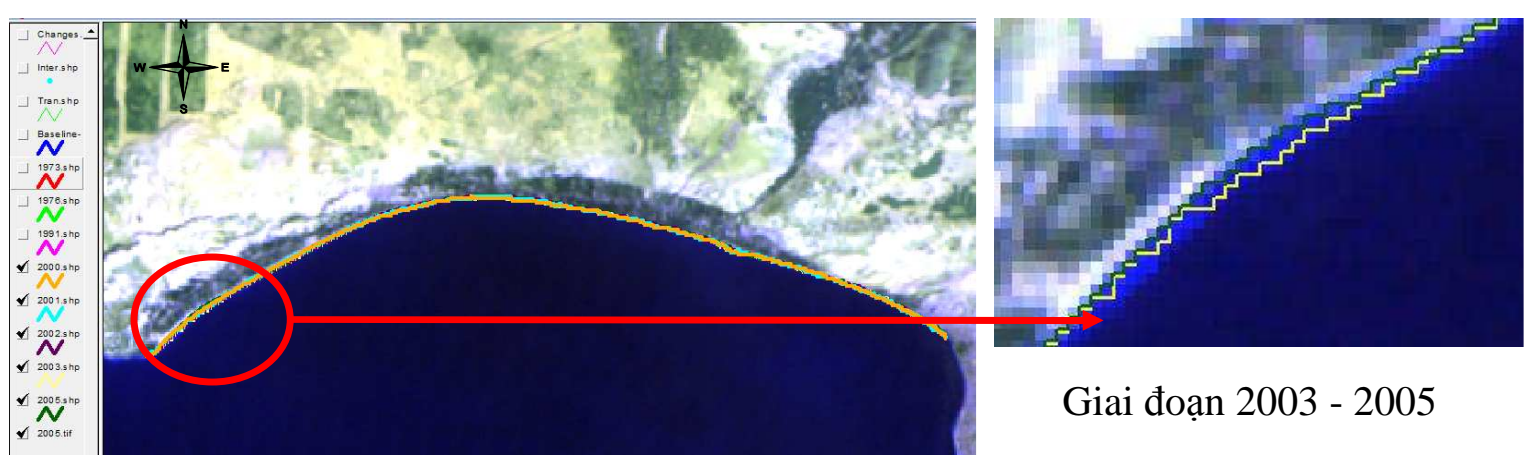

Hình 6: Sự thay đổi đường bờ khu vực 4 (Hàm Tiến) từ năm 2000 đến 2005 
Một số kết quả phân tích ở trên cho thấy khu vực Đồi Dương có sự thay đổi đường bờ gần cửa sông khá phức tạp theo thời gian. Việc tính toán định lượng tốc độ xói lở bồi tụ sẽ không hiệu quả nếu như phần doi cát ở Đồi Dương được tính toán như là một phần của đường bờ. Từ hạn chế đó, việc tính toán tốc độ thay đổi đường bờ chỉ thực hiện cho khu vực 4 hay khu vực Hàm Tiến, bỏ qua khu vực Đồi Dương. Sau đây là một số kết quả tính toán định lượng sự thay đổi đường bờ từ DSAS cho khu vực Mũi Né (hình 7,8).

Hình 7 trình bày các đường bờ từ 1973 đến 2005 và các transect sử dụng trong DSAS. Khu vực tính toán dài $11.200 \mathrm{~m}$ và có tổng cộng 112 transect. Các transect được xây dựng dọc đường bờ khu vực Hàm Tiến và được đánh số theo thứ tự tăng dần từ trái qua phải. Khoảng cách mỗi transect là $100 \mathrm{~m}$ và độ dài mỗi transect là $300 \mathrm{~m}$. Khu vực này được tính toán riêng lẻ trong hai giai đoạn: giai đoạn 1973 - 2000 và giai đoạn 2000 2005.

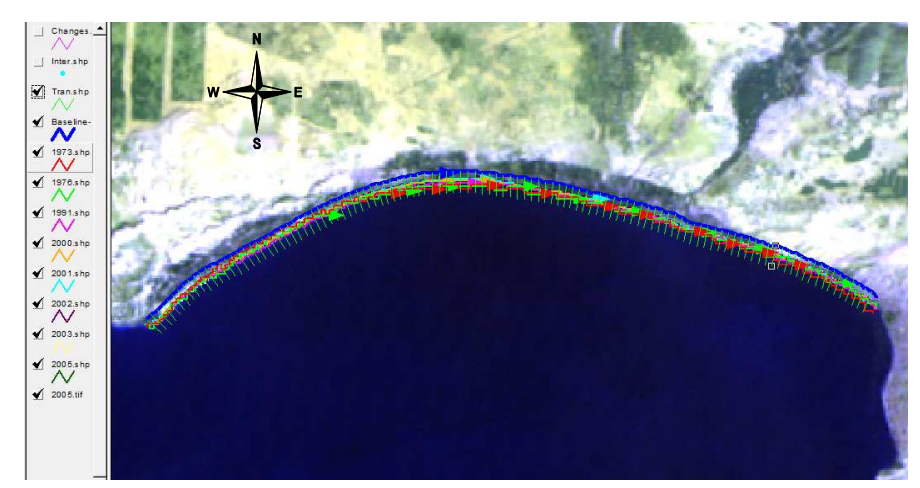

Hình 7: Xây dựng transect tại khu vực 4 (Hàm Tiến) từ năm 1973 đến 2005

Hình 8 trình bày các biểu đồ biểu thị tốc độ thay đổi đường bờ khu vực Hàm Tiến tương ứng với các giai đoạn 1973 - 2000 ở phía bên trái và giai đoạn 2000 - 2005 ở phía bên phải. Trên các biểu đồ, giá trị dương biểu thị cho tốc độ bồi tụ hàng năm và giá trị âm biểu thị cho tốc độ xói lở hàng năm. Kết quả tính toán cho thấy trong giai đoạn 1973 2000 , đoạn bờ từ transect 1 đến transect 36 có xu hướng bồi hàng năm với tốc độ trung bình $+2 \mathrm{~m}$. Từ transect 36 đến transect 112 có tốc độ xói lở trung bình hàng năm gần $-2 \mathrm{~m}$. Tốc độ thay đổi đường bờ trung bình cho cả khu vực Hàm Tiến đạt giá trị là $0 \mathrm{~m} / \mathrm{năm}$ trong giai đoạn từ 1973 đến 2000 . Nhìn chung, đường bờ có xu hướng cân bằng. Trong giai đoạn 2000 - 2005, đường bờ cả khu vực Hàm Tiến có xu hướng xói lở cao với tốc độ trung bình gần -4 m/năm. 


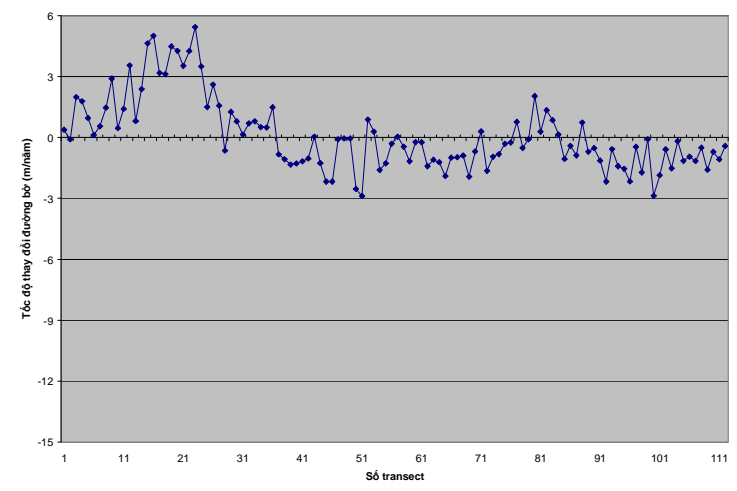

Giai đoạn 1973 - 2000

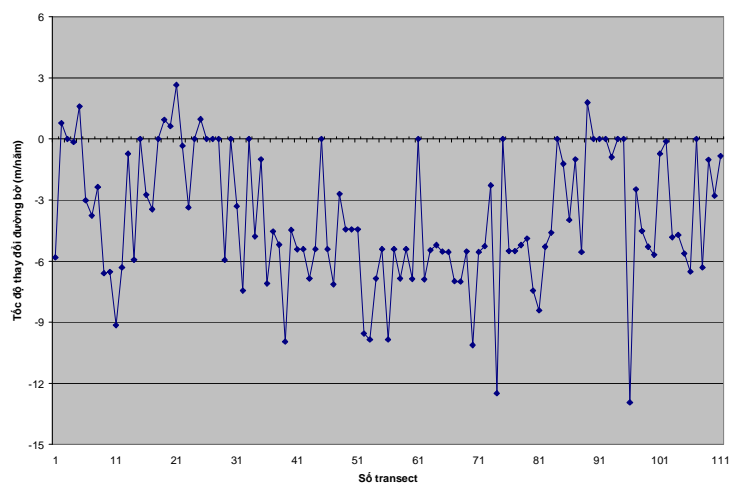

Giai đoạn 2000 - 2005

Hình 8: Tốc độ thay đổi đường bờ khu vực Hàm Tiến giai đoạn 1973 - 2000 và giai đoạn 2000 - 2005

\section{KẾT LUẬN}

Với sự trợ giúp đắc lực của công nghệ viễn thám và GIS, việc theo dõi và tính toán sự thay đổi đường bờ được thực hiện nhanh chóng và dễ dàng hơn. Kết quả phân tích ảnh cho thấy hai khu vực có nhiều biến đổi nhất là Đồi Dương và Hàm Tiến. Đối với Đồi Dương, khu vực này có nhiều biến động tại hai cửa sông. Tuy nhiên, sự thay đổi dần ổn định sau khi các kè cảng được xây dựng. Đối với Hàm Tiến, quy luật thay đổi đường bờ bắt đầu từ cuối thập niên 90 của thế kỷ trước khi sự phát triển của dịch vụ du lịch bắt đầu nở rộ. Việc xây dựng các đê biển không đồng nhất của các khách sạn và khu nghỉ dưỡng đã làm đường bờ nơi đây diễn biến phức tạp. Từ DSAS, tính toán định lượng cho thấy, tốc độ thay đổi đường bờ hàng năm trong giai đoạn 1973-2000 xấp xỉ $0 \mathrm{~m}$, còn trong giai đoạn 2000 - 2005 là gần -4 m.

Việc rút trích tự động hoặc bán tự động thông tin từ ảnh viễn thám cho phép ta tiết kiệm thời gian và nguồn nhân lực rất nhiều so với việc đo đạc thực địa truyền thống ngoài hiện trường. Tuy nhiên, một số thông tin đó cần phải được hiệu chỉnh thêm như các điểm khống chế mặt đất, thông tin về dao động triều, địa hình đáy... để có được nguồn dữ liệu đường bờ hữu ích và chính xác hơn. Bên cạnh đó, cần phải có nguồn ảnh có độ phân giải cao hơn để thấy được các biến động nhỏ cục bộ. Từ đó làm cơ sở cho việc tính toán tốc độ thay đổi đường bờ bằng mô hình số trị hoặc bằng công nghệ GIS.

Các kết quả đạt được ở trên phần nào cho thấy khả năng áp dụng công nghệ viễn thám và GIS để đánh giá biến động đường bờ cho các khu vực khác ở Việt Nam. 


\section{TÀI LIỆU THAM KHẢO}

1. Bùi Hồng Long và cộng sụ̣, 2000. Điều tra các điều kiện tự nhiên, môi trường, nguồn lợi vùng ven bờ vịnh Phan Thiết và xây dựng định hướng chính phát triển bền vững kinh tế - xã hội địa phương. Viện Hải dương học Nha Trang.

2. Dang Vang To, 2006. Beach Erosion in Doi Duong - Phan Thiet Tourist Resort and Its Proposed Measure, Vietnam-Japan Estuary Workshop, Vietnam: 151-156.

3. Dang Van To and Pham Thi Phuong Thao, 2008. A Shoreline Analysis using DSAS in Nam Dinh Coastal Area, International Journal of Geoinformatics, 4(1): 37-42.

4. Đặng Văn Tỏ và Phạm Thị Phương Thả, 2008. Xác định đường mực nước từ ảnh số, Tuyển tập Báo cáo Khoa học Hội nghị Khoa học "Biển Đông-2007”, Viện Hải dương học Nha Trang: 591-600.

5. Holman, R. A., Sallenger, A. H., Lippmann, T. C. and Haines, J. W., 1993. The Application of Video Image Processing to The Study of Nearshore Processes, Oceanography, 6(3), pp. 78-85.

6. Li, R., 1997. Mobile Mapping: An Emerging Technology for Spatial Data Acquisition, Photogrammetric Engineering and Remote Sensing, 63(9): 1165-1169.

7. Nguyen Hanh Quyen, Tran Minh Y, Le Thi Thu Hien, 2004. Using Remote Sensing Techniques for Coastal Zone Management in HaLong Bay (Vietnam), Proceedings of International Symposium on Geoinformatics for Spatial Infrastructure Development in Earth and Allied Sciences: 151-156.

8. Nguyễn Tứ Dần, Nguyễn Thế Tiệp, 2003. Xu thế biến động của các cửa sông chính ở dải ven biển đồng bằng sông Hồng, Tạp chí Khoa học và Công nghẹ biển, T3, Số 1: 25-35.

9. Pham Bach Viet, Truong Ngoc Tuong, Nguyen Thanh Minh, 2004. Using TimeSeries Remotely Sensed Data to Trace Historical Changes of LocAn River Mouth Area, Proceedings of International Symposium on Geoinformatics for Spatial Infrastructure Development in Earth and Allied Sciences: 172-177.

10. Phạm Thị Phương Thảo, Hồ Đình Duẩn và Đặng Văn Tỏ, 2009. Biến động đường bờ khu vực Mũi Né, Kỷ yếu Kỷ niệm 25 năm ngày Thành lập Viện Co học và Tin hoc Úng dung, Tp. HCM: 334-337.

11. Phan Văn Hoặc, 1986. Các đặc trung khí tuoọng-hải-thủy văn vùng biển Phan Thiết. 
12. Tanaka, H., 2006. Monitoring of Short-term Morphology Change at A River Mouth, Vietnam-Japan Estuary Workshop, Vietnam: 1-6.

13. Thieler, E. R., Martine, D., and Ergul, A., 2003. The Digital Shoreline Analysis System, Version 2 Shoreline Change Measurement Software Extension for ArcView, USGS. Open-File Report 03-076.

14. Tran Thi Van, Trinh Thi Binh, 2008. Shoreline Change Detection to Serve Sustainable Management of Coastal Zone in Cuu Long Estuary, International Symposium on Geoinformatics for Spatial Infrastructure Development in Earth and Allied Sciences: 351-356.

15. http://www.aars-acrs.org/acrs/proceeding/ACRS1989/Papers/OCN89-1.htm

16. Pham Viet Cuong, Nguyen Hong Chau, Tran Minh Hien, 1989. Application of Remote Sensing Imagery for Investigation in the Haiphong Estuarine and Coastal Zone, Proceeding of Asian Association on Remote Sensing.

\title{
APPLICATION OF REMOTE SENSING AND GIS FOR CALCULATING THE COASTLINE CHANGES IN PHAN THIET
}

\author{
PHAM THI PHUONG THAO, HO DINH DUAN, DANG VAN TO
}

Summary: By integrating remote sensing with GIS, the monitoring and calculation of shoreline changes are carried out quickly and effectively. With multi-temporal Landsat imageries, preliminary view is outlined about shoreline change in Phan Thiet from 1973 to 2004. In addition, by the extension of ArcView, DSAS, shoreline change rates are calculated in Ham Tien area before and after some coastal constructions were built.

Ngày nhận bài: 18 - 10 - 2010

Ngườ nhận xét: TS. Nguyễn Bá Xuân 